\title{
Origami Applications in Structural Engineering: A Look at Temporary Shelters
}

\author{
Monica Norman, Kaveh Arjomandi \\ University of New Brunswick \\ 17 Dineen Drive, Fredericton, Canada \\ monica.norman@unb.ca; kaveh.arjomandi@unb.ca
}

\begin{abstract}
Origami is an ancient Japanese art that has been circling the globe for centuries. In past, it was used to create simple objects, however, more recent applications have been transitioning through mathematics to science and engineering. Inspirations from origami in the scientific community have led to developments in deploying structures in space, transporting medical devices through the human body, or creating easily foldable and portable shelters. This paper focuses on origami principles applied to structural engineering, in particular, temporary shelters for use in dire situations. Primary motivation comes from the need for sound temporary housing distributed within refugee camps. Three shelters with the following geometries were created: the Yoshimura (diamond) pattern in a tunnel shape, the diamond pattern in a dome shape, and a variation of the Miura-Ori pattern in a tunnel shape. Finite element models of the structures were developed using SAP2000; the models were simulated using Eigenvalue buckling analysis in addition to non-linear static analysis methods. Stress analysis results were used to design the shelters' panel thickness to be made from highdensity polyethylene (HDPE). In addition to the detailed analysis and design results, this paper provides a comparison study of the structural integrity of the three investigated folds. This can potentially benefit the development of lightweight, portable, and sound temporary shelters made use of in severe situations.
\end{abstract}

Keywords: Origami, Temporary Shelter, Finite Element Method, Yoshimura, Miura-Ori

\section{Introduction}

The word origami is a derivative of 'oru' and 'kami' from the Japanese language, which mean 'to fold' and 'paper' respectively [1]. The practice was created in ancient times by the Japanese as both an art and as a recreational platform [2]; folding a single sheet of paper into a unique shape resulted in household decorations as well as toys for children to play with. Throughout history, origami shapes and patterns have become more complex and in some cases, have been introduced to kinetic movements. Origami objects can be as simple as a traditional letter envelope, or as complex as a robotic arm.

As origami has transformed in complexity, it has made a transition from purely an art-based practice to a motivation for many scientists. Using basic origami principles and mathematical relationships, the origami practice has developed into a complex art that inspires many other applications from robotics, to space structures, to medical devices. Robert J. Lang has been a very large influence in this evolution alongside many other researchers and developers such as Tomohiro Tachi, John Montroll, Jun Maekawa, and Toshikazu Kawasaki [3][4]. Using computational methods, Lang was able to develop an algorithm to transform a simple stick figure into a crease pattern, which can then be folded into a sophisticated origami figure [5]. Other mathematicians have focused on the relationship between the length of a line segment and a crease in a sheet of paper; an example of this type of relationship is that from folding a square sheet of paper diagonally in half, the square root of two is created [3]. This knowledge has created a bond between origamists and scientists.

The scope of this study is motivated by the works of these individuals in an attempt to connect origami with structural engineering. In particular, temporary structures constructed by means of origami will be looked at as an option to provide shelter in dire situations, which may include post-disaster shelters, internal displacement camps, and refugee camps. Primary focus will be put on temporary shelters distributed to refugees and asylum seekers upon entering a refugee camp. 


\section{Background in Origami}

\subsection{Origami Definitions}

The following definitions are commonly used in origami folds $[1,2,11,12]$ :

Crease: A localized fold in a sheet that has since been unfolded;

Crease Pattern: The creases shown on a sheet after an origami shape has been unfolded;

Faces: The regions contained by creases;

Folded Shape: The final object as a result of completing the folding of a crease pattern;

Folding Pattern: A schematic that identifies all creases needed to fold an object;

Mountain Fold: To fold the sheet behind itself such that the crease is elevated with respect to the adjacent faces;

Node, Vertex, or Joint: The end point of a line or the point at which two or more creases meet;

Reverse Fold: A combination of mountain and valley folds created by inverting a portion of the original crease;

Valley Fold: To fold the sheet over itself such that the adjacent faces are elevated with respect to the crease.

\subsection{Origami Principles}

All origami objects can be attributed to three types of folds: mountain folds, valley folds, and unfolds. Using these three types of folds, a continuum of angles can be created, adding dimension and dissimilarity between folds [11]. Mountain and valley folds can also be combined to create other folds such as a reverse fold or a pleated fold.

The mathematical relationships that describe an origami crease pattern amount to four basic principles [4]. First, Maekawa's Theorem explains that at any vertex in a crease pattern, the number of mountain folds must always differ by two from the number of valley folds. Second, Kawasaki's Theorem states that the alternating angles between creases surrounding any vertex sum to $180^{\circ}$. Third, two-colorability applies to any crease pattern; if the entire pattern were coloured with only two colours, the same colour would never meet along a crease. Finally, when layering folds and sheets, a sheet cannot infiltrate a crease at overlaps in the pattern [5].

\subsection{Current Applications of Origami in Structural Engineering}

Origami concepts and patterns are becoming more popular in engineering applications with growing exposure of the art into science. Presently, origami principles have inspired designs in space science applications, robotics, biomedical functions, solar energy practices, aircrafts, and temporary structure design [1] [2] [3].

Basic origami principles are commonly found in pole structures such as camping tents or canopy event tents where the frame folds into smaller sections and the plastic cover can be folded manually. The integration of origami in engineering has allowed temporary shelter concepts to be expanded. An example is the Accordion ReCover Shelter, developed by Matthew Malone, Amanda Goldberg, Jennifer Metcalf, and Grant Meacham. This shelter was designed for emergency response purposes and is created entirely out of polypropylene [6]. The shelter can be folded and unfolded in a similar manner to the action of an accordion and can be packaged in two different shapes for ease of shipping.

Another origami inspired shelter is the Origami Cave, a design based on a water molecule with flat panels that form the 3-dimensional shape [7]. As developments continue, origami shelters are becoming a large part of how victims of a disaster find refuge; they are changing how we perceive a shelter in addition to the ways in which they are designed.

\section{Refugee Camps, A Case Study of Kapise Refugee Camp in Malawi}

Malawi is a land-locked country in the south-eastern region of Africa near countries including Mozambique, Democratic Republic of the Congo, Burundi, Rwanda, Kenya, and Tanzania. In the past decade, civil unrest has been significantly rising in these surrounding countries and Malawi has been looked to for refuge. Recently, Malawi in partnership with the United Nations High Commissioner for Refugees (UNHCR) have reopened refugee camps in the country in order to accommodate those fleeing their home countries and wishing for asylum [8]. Three refugee camps currently exist in Malawi: Dzaleka Refugee Camp, located in central Malawi near the capital of Lilongwe, Luwani Refugee Camp, located in the south-eastern part of the country, and Kapise Transit Camp, located in the southern-western part of the country near the border shared with Mozambique.

Kapise Refugee Camp is used as a transition for refugees before enduring the journey to Dzaleka or Luwani [9]. This camp provides a much more temporary situation than does Dzaleka Refugee Camp and accommodates large volumes of short-term visitors. Due to the short turnover period, refugees reside primarily in tent shelters as opposed to a more permanent dwelling. The United Nations Operational Satellite Applications Programme (UNOSAT) under the United 
Nations Institute for Training and Research (UNITAR), collected data against satellite imagery in order to determine the type of structures within the Kapise refugee camp. This data shows that $50.3 \%$ of shelters in this camp are tent shelters and 44.3\% are improvised shelters [10]. These shelters are predominantly made of grass thatch or wooden poles covered by a sheet of plastic distributed by the UNHCR. Although Kapise is considered a transit camp, many refugees continue to reside in this camp for several years, and have to rebuild their home several times within that period. These tents are unable to provide the proper privacy and shelter from the elements that refugees wish for to be able to feel secure. Figure 1 shows a typical shelter constructed from wooden posts, grass thatch, and tarpaulins located in refugee camps in Malawi [14].
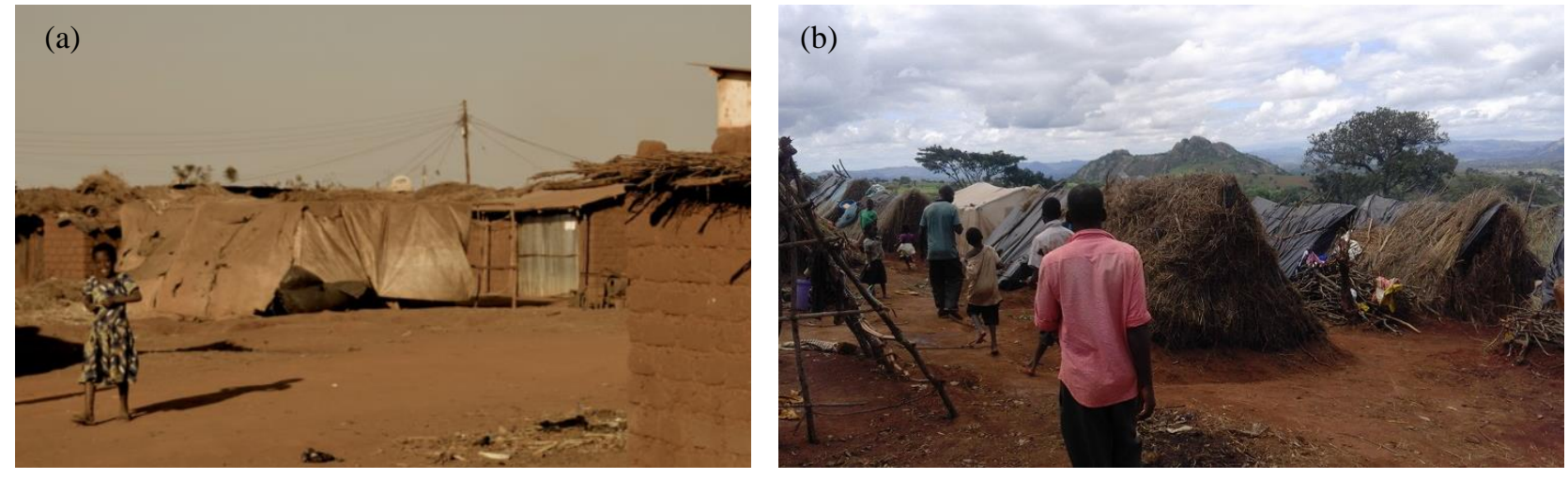

Fig. 1: (a) Dzaleka Refugee Camp in Malawi; (b) Typical Dwelling in Kapise Transit Camp, Malawi.

\section{Studied Shelter Structures}

\subsection{Temporary Shelter Design Criteria}

In this study, five design criteria are followed in determining the appropriate crease pattern, geometry, and material for a temporary shelter. These design criteria include: (i) the shelter must be easily expandable and collapsible, (ii) the shelter must be comfortable for at least five persons, (iii) the height of the shelter must be adequate for the height of an average adult, (iv) the support conditions must reflect those experienced in reality, and (v) the material must be sufficient to withstand the natural elements.

\subsection{Shelter Geometry}

Three different shapes and folding patterns were used in order to encompass various shelter functions and to serve as a means of comparison between crease patterns and structural integrity. The first crease pattern used is the Yoshimura diamond pattern, where the geometry is composed of two adjacent triangles that form a diamond shape. The second crease pattern chosen is the Miura-Ori pattern, also called the Herringbone pattern. This pattern integrates several adjacent reverse folds in order to obtain the final geometry. Two different overall shelter shapes were chosen including a tunnel form, with either a round or square cross-section, and a dome profile. Combined with the indicated crease patterns, three shelters were developed: Yoshimura pattern with a cylindrical shape, Yoshimura pattern in the form of a dome, and a Miura-Ori variation with a square tunnel projection. Figure 2 depicts each of the shelter geometries in their fully expanded forms.

(a)

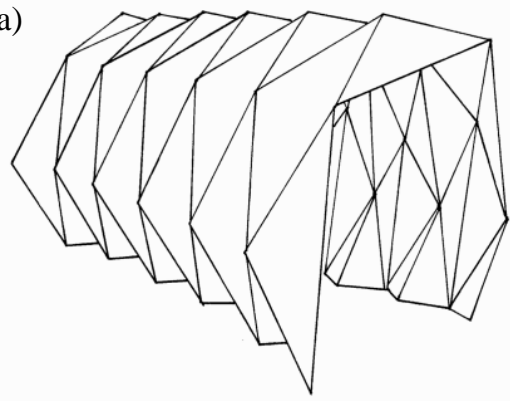

(b)

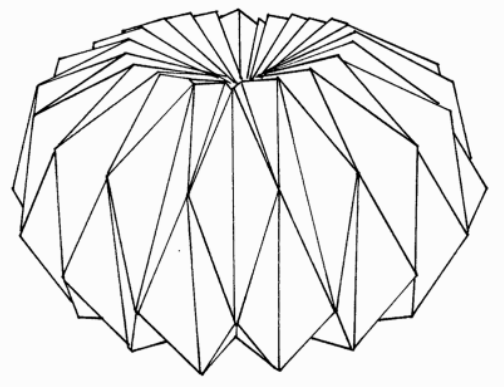

(c)

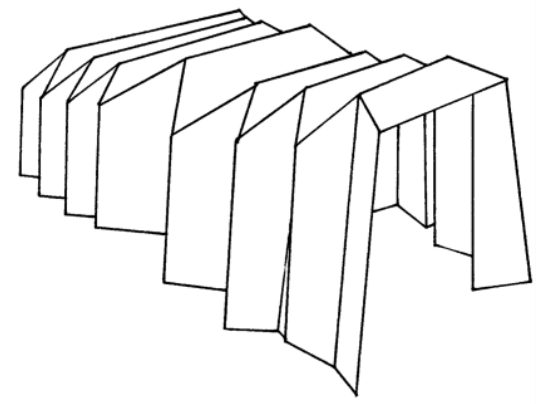

Fig. 2: (a) Yoshimura Tunnel Shelter: Clear Dimensions $10 \mathrm{~m}$ by $2.5 \mathrm{~m}$ by $2.5 \mathrm{~m}$ (LxWxH); (b) Yoshimura Dome Shelter: Clear Dimensions $9 \mathrm{~m}$ by 4.5m (DxH); (c) Miura-Ori Tunnel Shelter: Minimum Clear Dimensions $11.25 \mathrm{~m}$ by $2 \mathrm{~m}$ by $2.5 \mathrm{~m}$ (LxWxH). 


\subsection{Material}

The material chosen for this study was High-Density Polyethylene (HDPE). The appropriate engineering properties, including Modulus of Elasticity and Yield Stress, are noted in Table 1 [13]. HDPE was selected primarily due to its low density, thus being a lightweight material for transport. In addition, HDPE exerts waterproofing qualities that are important for sheltering the inhabitants from the elements.

Table 1: Engineering Properties of High-Density Polyethylene (HDPE)

\begin{tabular}{|l|c|}
\hline Engineering Property & Value \\
\hline Density, $\rho$ & $0.95 \mathrm{~g} / \mathrm{cm}^{3}$ \\
\hline Shear Modulus, $\mathrm{G}$ & $147.5 \mathrm{MPa}$ \\
\hline Modulus of Elasticity, E & $413 \mathrm{MPa}$ \\
\hline Poisson Ratio, $\mathrm{U}$ & 0.4 \\
\hline Yield Stress, $\sigma_{\mathrm{y}}$ & $31.7 \mathrm{MPa}$ \\
\hline Coefficient of Thermal Expansion, $\alpha$ & $12 \times 10^{-5} \mathrm{~m} / \mathrm{m} /{ }^{\circ} \mathrm{C}$ \\
\hline
\end{tabular}

\section{Finite Element Simulation}

The shelter structures were modelled using shell elements in SAP2000 (Figure 3). For the purpose of this analysis, gravitational distributed forces, gravitational nodal forces, and lateral nodal forces were considered, as these are common loading scenarios a temporary shelter might experience. For example: gravitational distributed forces account for the self weight of the structure, gravitational nodal forces account for snow load or rain load, and lateral nodal forces account for wind load. Point loads were applied to the joints simultaneously (Figure 4) in order to simplify analysis procedures. Gravitational distributed forces were applied as a self-weight multiplier. Since the geometries of the shelters are very complex, point loads were applied to the joints, and an average panel stress as a result of point loading was evaluated. The stress analysis accounted for non-linear P-delta effects plus large displacements experienced by the area elements and respective nodes. In the formulation of load-displacement relationships, lateral notional loads were also considered when gravitational nodal forces were applied to the shelters.
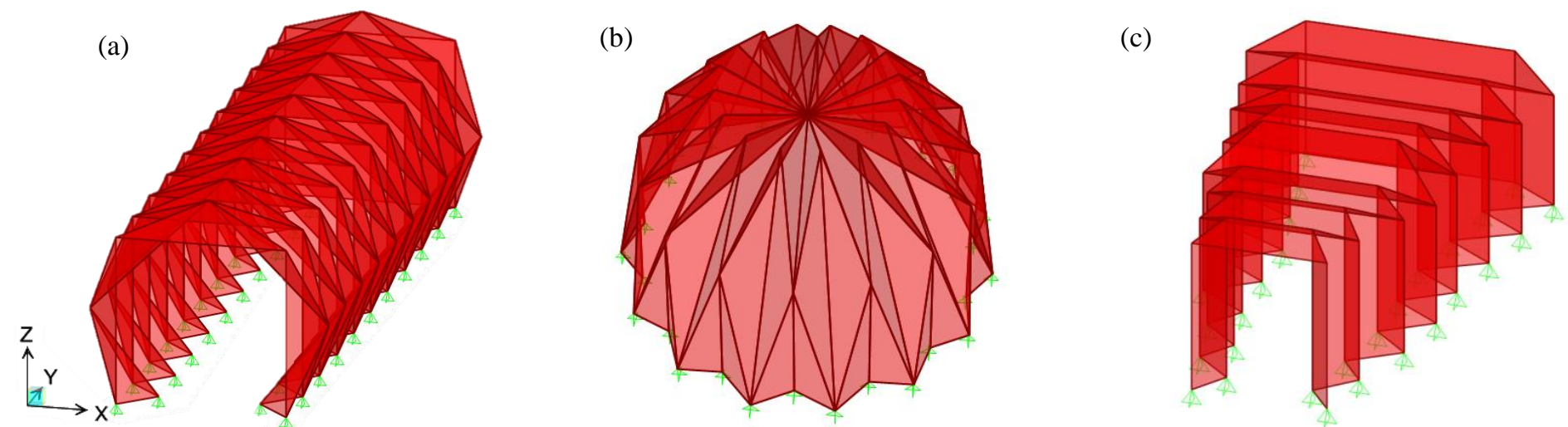

Fig. 3: Shelter Structures Modelled in SAP2000 in an Undeformed Shape, (a) Yoshimura Tunnel Shelter; (b) Yoshimura Dome Shelter; (c) Miura-Ori Tunnel Shelter.

Polyethylene was modelled using linear elastic material with a thickness of $1 / 4$ inch. Foundation points between the shelter and the ground surface were considered as pin connected supports in order to restrict lateral movement but to allow rotation. For a temporary shelter that must be easily transportable, pin supports are the most representative scenario in physical construction of the shelters. Stress analysis was performed using the SAP2000 program and the results were postprocessed using Microsoft Excel. The maximum load case for each area element was determined; the stress experienced by the area element for the governing load case was calculated by averaging the stress occurring at the adjacent joints. The average stress $\left(\sigma_{\text {avg }}\right)$ was then compared against the yield stress $\left(\sigma_{\mathrm{y}}=31.7 \mathrm{MPa}\right)$ of HDPE in order to determine the safety factor (SF) with respect to area stresses.

In addition to a non-linear static P-delta analysis, an Eigenvalue buckling analysis was performed for each shelter. The load patterns were modified in SAP2000 to account for a total of 10 buckling modes. Buckling factors (k) were produced 
for gravitational distributed loads, gravitational nodal loads, and lateral nodal loads independently. The buckling factors were recorded in conjunction with the buckling shape of each buckling mode. Furthermore, the relationship between applied loadings and critical nodal displacements were studied. The maximum displacement in the three orthogonal directions was determined for each incremental gravitational and lateral load independently. These values were used to create a stiffness envelope for each origami shelter.
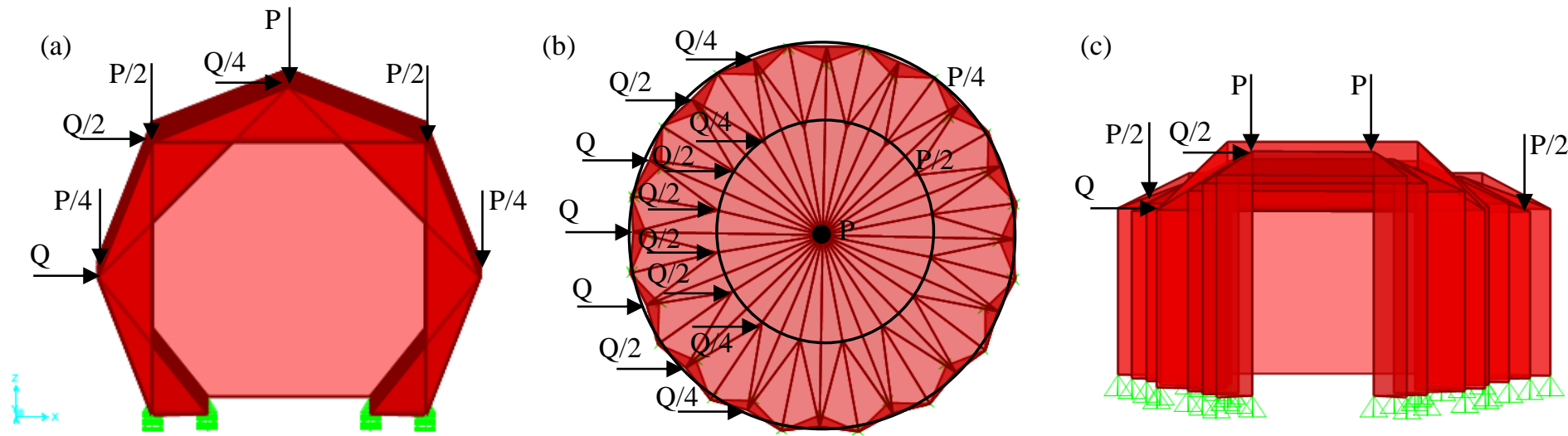

Fig. 4: Load Patterns Applied to Shelter Models in SAP2000, (a) Yoshimura Tunnel Shelter; (b) Yoshimura Dome Shelter; (c) MiuraOri Tunnel Shelter.

\subsection{Eigenvalue Buckling Analysis Results}

For each shelter, the gravitational nodal loads proved to be the governing load type for which the shelter would buckle. Under such loads, the primary buckling factor for the Yoshimura tunnel shelter, Yoshimura dome shelter, and Miura-Ori tunnel shelter was 8.62, 29.34, and 3.68 respectively. The first three buckling mode shapes for the Yoshimura tunnel shelter were lateral buckling in $\mathrm{x}$, torsional buckling, and lateral buckling in $\mathrm{y}$. The Yoshimura dome shelter underwent lateral buckling in $\mathrm{x}$, lateral buckling in $\mathrm{y}$, and torsional buckling as the first three buckling shapes respectively. Finally, the Miura-Ori tunnel shelter experienced lateral buckling in $\mathrm{x}$ as the first buckling mode and lateral buckling in $\mathrm{y}$ as the second and third buckling mode shapes. The critical buckling mode occurred under gravitational nodal forces $(\mathrm{P})$ in all shelters (Figure 5) with buckling load capacities of $431 \mathrm{kN}, 1467 \mathrm{kN}$, and $184 \mathrm{kN}$ respectively.
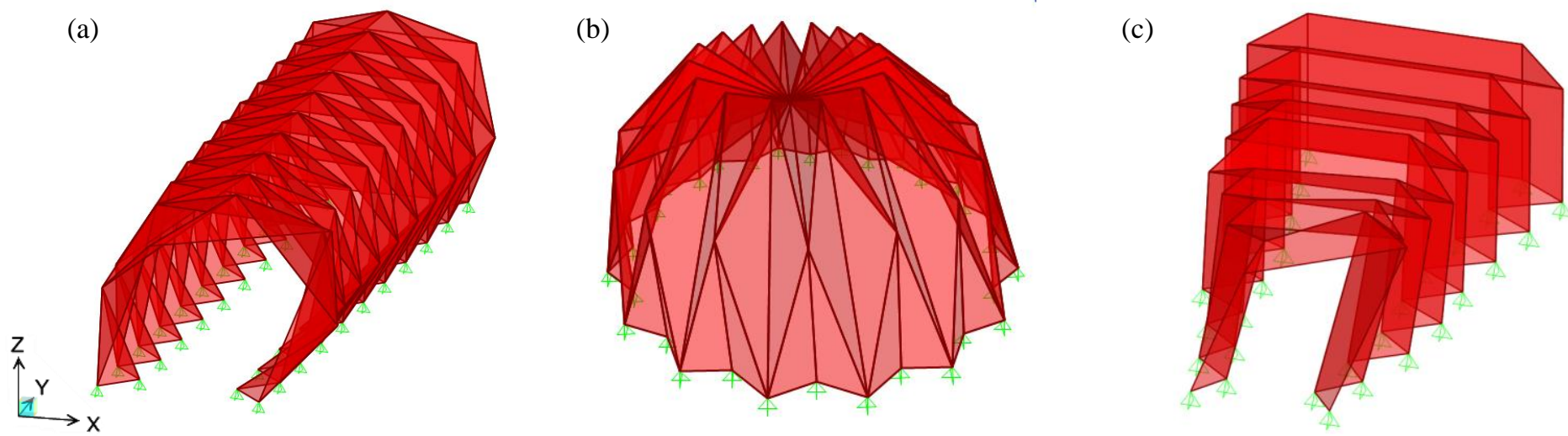

Fig. 5: Critical Buckling Mode Shapes with a Scale Factor of 10 Applied, (a) Yoshimura Tunnel Shelter; (b) Yoshimura Dome Shelter; (c) Miura-Ori Tunnel Shelter.

\subsection{Large-Displacement Non-Linear Analysis Results}

Conducting a non-linear stress analysis in SAP2000 yielded the maximum stress at each node of the shelter, which was then used to determine the maximum average stress in each area element. These stress values were computed under a combined loading of $50 \mathrm{kN}$ gravitational nodal forces and $20 \mathrm{kN}$ lateral nodal forces, which were then compared against the yield stress of HDPE. Due to the complexity of geometry in the shelters and limitations of SAP2000, direct collection of the maximum average stress under a tributary area was hindered. For the Yoshimura tunnel shelter, the governing safety factor was 5.02, occurring in the bottom left element near the entrance of the shelter. For the Yoshimura dome shelter, the 
governing safety factor was 18.71 , occurring in an element connected to two supports. A value of 6.24 was determined to be the governing safety factor for the Miura-Ori tunnel shelter, corresponding to a roof panel near the rear of the shelter.

\subsubsection{Force-Displacement Relationships Under Gravitational Loading}

Under gravitational loading, the Yoshimura tunnel shelter shows a behaviour that follows both a linear and non-linear pattern. First, the nodal deflections increase semi-linearly as load increases with a fairly large stiffness. When the load (P) reaches approximately $425 \mathrm{kN}$, the structure softens and a plateau is reached. The structure then experiences hardening when the load is increased to $475 \mathrm{kN}$. This graphical relationship is shown in Figure 6(a), where the colour orange identifies displacements in $\mathrm{x}$, blue identifies displacements in $\mathrm{y}$, and green identifies displacements in $\mathrm{z}$.

(a)

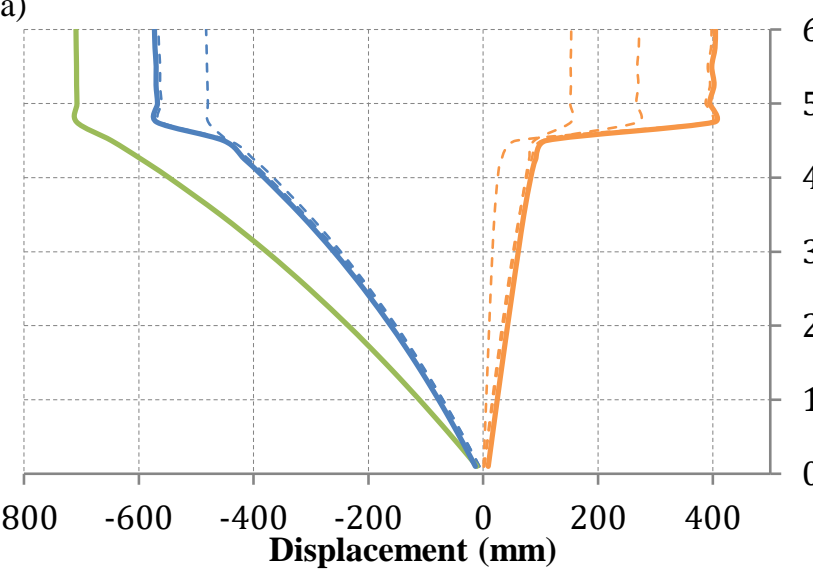

(c)

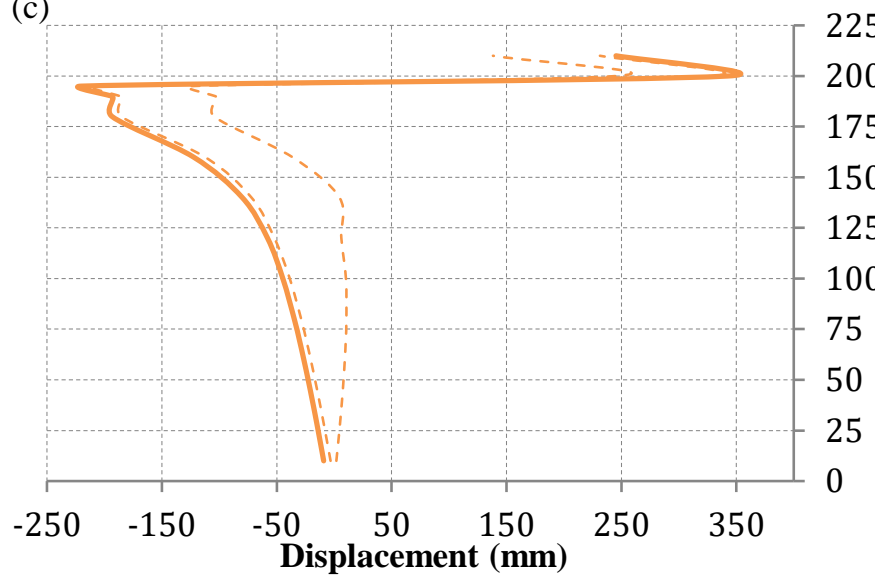

(b)

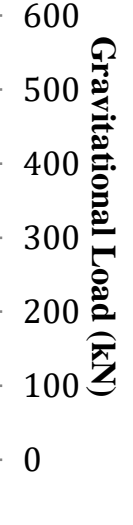

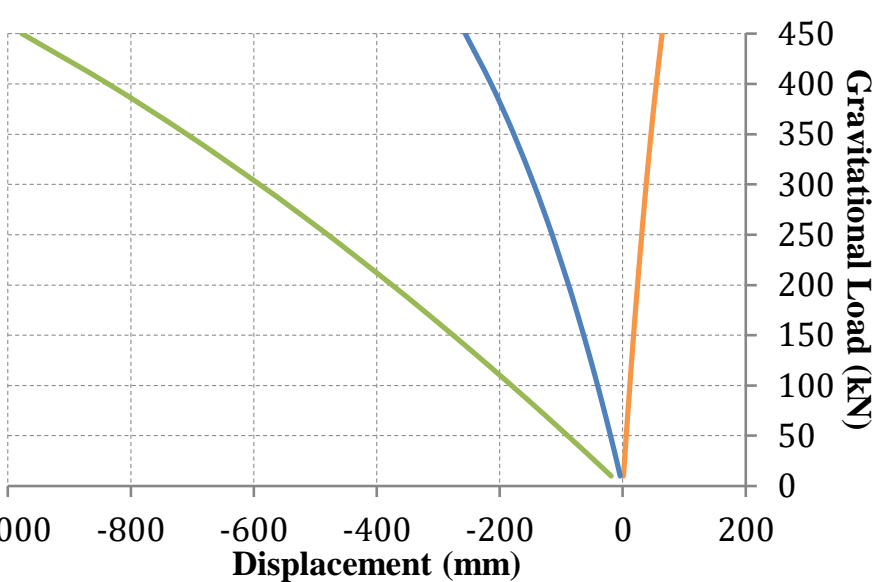

(d)

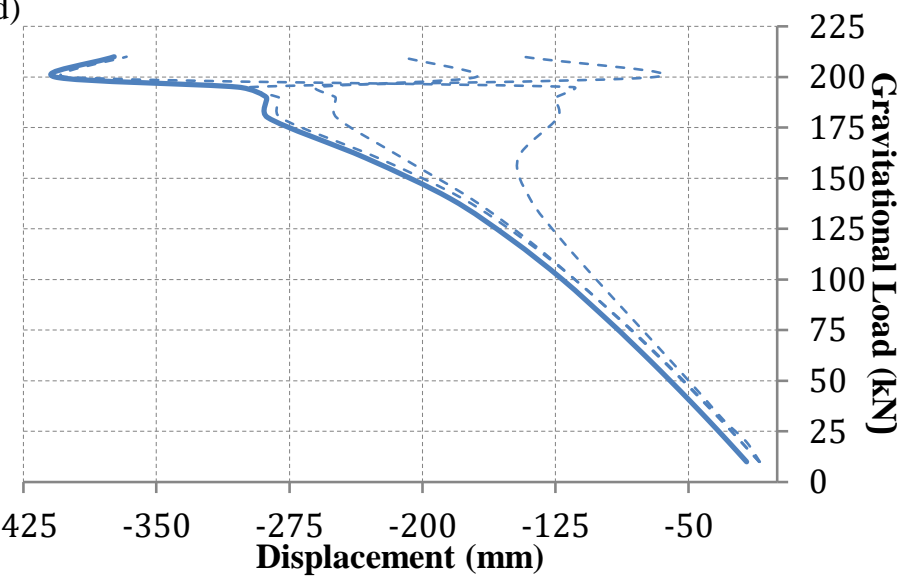

(e)

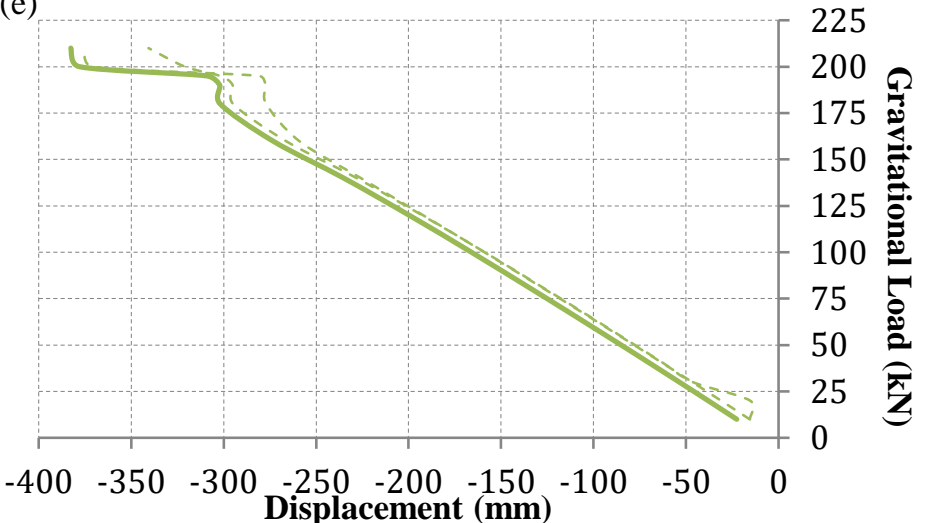

Fig. 6: Load-Displacement Relationship Subjected to Gravitational Loads- Orange, Blue, and Green Represent Displacements in X, Y, and Z Respectively, (a) Yoshimura Tunnel Shelter; (b) Yoshimura Dome Shelter; (c) Miura-Ori Tunnel Shelter in X; (d) Miura-Ori Tunnel Shelter in Y; (e) Miura-Ori Tunnel Shelter in Z. 
The Yoshimura dome shelter follows a slightly more predictable behaviour. The shelter deforms semi-linearly in the three orthogonal directions under gravity loads, with the greatest deflections occurring along the z-axis. The centre node, Node 1, is shown to be the most critical with only slight deflections in $\mathrm{x}$ and $\mathrm{y}$ as seen in Figure 6(b).

The Miura-Ori tunnel shelter shows perhaps the most complexity. The $\mathrm{x}, \mathrm{y}$, and $\mathrm{z}$ directions all show several critical nodes within the limits of the investigation. For deformations in $\mathrm{x}$ (Figure 6(c)), the critical behaviour is highly non-linear under large loads. Between loads of $195 \mathrm{kN}$ and $200 \mathrm{kN}$, the shelter transforms from a governing negative displacement to a positive displacement. Three critical nodes exist under deformations in the y-axis (Figure 6(d)); the shelter experiences large softening periods and snap through behaviour, particularly between loads of $190 \mathrm{kN}$ and $200 \mathrm{kN}$. The behaviour of the Miura-Ori tunnel shelter in the z-axis (Figure 6(e)) follows a linear relationship more closely, with a slight period of hardening and softening above loads of $175 \mathrm{kN}$.

\subsubsection{Force-Displacement Relationships under Lateral Loading}

All of the shelters exhibit similar behaviour under lateral loads. The performance of the shelters corresponds to a slightly non-linear behaviour in each of the orthogonal directions, with the critical displacements occurring in the $\mathrm{x}$ direction. For the Yoshimura and Miura-Ori tunnel shelters, the stiffness in the y and z directions is greater than that in the $\mathrm{x}$ direction. For the Yoshimura dome shelter, however, $\mathrm{x}$ and y deformations experience very similar stiffness with the stiffness in $\mathrm{z}$ being much greater than the former. The graphical relationship of the Yoshimura tunnel shelter, Yoshimura dome shelter, and Miura-Ori tunnel shelter under lateral loading are depicted in Figure 7.

(a)

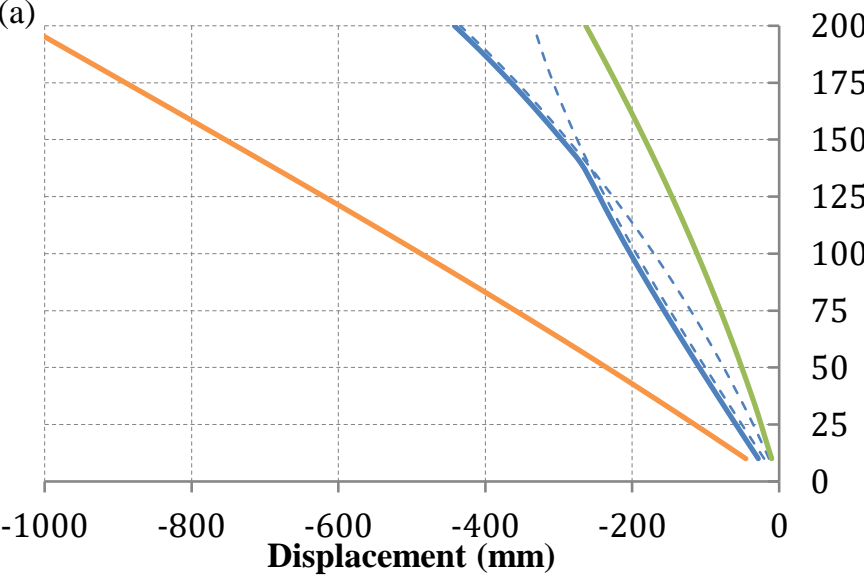

(b)

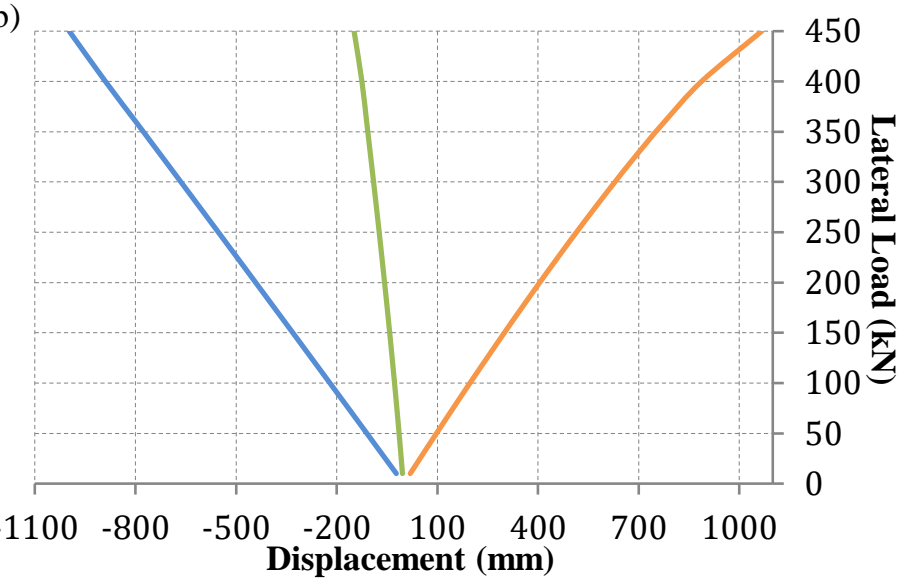

(c)

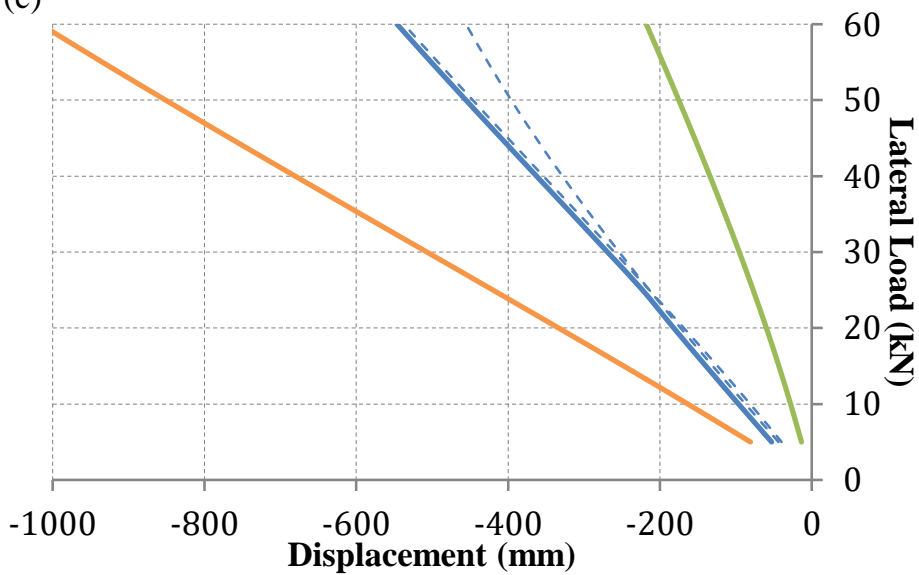

Fig. 7: Load-Displacement Relationship Subjected to Lateral Loads- Orange, Blue, and Green Represent Displacements in X, Y, and Z Respectively, (a) Yoshimura Tunnel Shelter; (b) Yoshimura Dome Shelter; (c) Miura-Ori Tunnel Shelter. 


\section{Concusions}

For a specific area element with a safety factor above 1.0, the element does not reach the yield capacity and thus experiences only elastic deformations; all of the shelters studied in this paper exhibited an elastic behaviour under the applied loads. Furthermore, it was identified from the load-displacement behaviour of the structures that the structural response is linear under small loads. Therefore, it can be concluded that although these structures exhibit a highly nonlinear load displacement behaviour in large deformations, the three investigated shelters exhibit linear elastic behaviour under small loads. The range of safety factors calculated for the Yoshimura tunnel shelter were between 5 and 70, between 19 and 1180 for the Yoshimura dome shelter, and between 19 and 800 for the Miura-Ori tunnel shelter. Inferring from these ranges among the three shelters, the Yoshimura tunnel shelter appeared to distribute stresses more evenly throughout the structure while the Miura-Ori tunnel shelter gave an impression of concentrated stresses in select areas.

The force-displacement relationships determined through analysis aid in predicting the behaviour of each shelter. The Yoshimura tunnel shelter experienced a period of hardening under large gravitational forces, which makes for a strong, stiff shelter. This could be beneficial in areas with high rain loads or snow loads. The Yoshimura dome shelter demonstrated nearly linear elastic behaviour under both gravitational and lateral loads. The Miura-Ori shelter was unable to withstand as intense of loading as the previous two shelter configurations while the structure experienced high nonlinearity. This can potentially be used in designing energy dissipation systems for seismic and wind loads.

Under the engineering properties described in Section 4.2, the mass of each shelter is $1046.7 \mathrm{~kg}, 1602.1 \mathrm{~kg}$, and $1235.6 \mathrm{~kg}$ respectively. Fully erected, the Yoshimura tunnel shelter occupies a volume of approximately $74 \mathrm{~m}^{3}$; the Yoshimura dome shelter occupies approximately $245 \mathrm{~m}^{3}$, and the Miura-Ori tunnel shelter occupies approximately $120 \mathrm{~m}^{3}$. Comparing the mass to volume yields $14.2 \mathrm{~kg} / \mathrm{m}^{3}, 6.3 \mathrm{~kg} / \mathrm{m}^{3}$, and $10.3 \mathrm{~kg} / \mathrm{m}^{3}$ for each shelter respectively. These figures imply that although the Yoshimura dome shelter has the largest weight, the structure is able to use the material and resulting space more efficiently.

Overall, the studied shelters exhibit promising performance in terms of suitable use as a temporary shelter; the behaviours discovered through this project provide a good foundation for future studies and to be able to develop an origami shelter that is appropriate for situations such as those experienced by refugees.

\section{References}

[1] L. J. Fei and D. Sujan, "Origami Theory and its Applications: A Literature Review," International Journal of Social, Behavioral, Educational, Economic, Business, and Industrial Engineering, vol. 7, no. 1, pp. 229-233, 2013.

[2] E. Peraza-Hernandez, D. Hartl, R. Malak, and D. Lagoudas, "Origami-inspired active structures: a synthesis and review," Smart Materials and Structures, vol. 23, 2014.

[3] R. J. Lang, "The Science of Origami,” Physics World, pp. 30-31, 2007.

[4] R. J. Lang, "Origami Design Secrets: Mathematical Methods for an Ancient Art," The Mathematical Intelligencer, vol. 25, no. 2, pp. 92-95, 2005.

[5] R. J. Lang. (2008, Feb.). The Math and Magic of Origami, [Online]. Available: http://www.ted.com/talks/robert_lang_folds_way_new_origami

[6] E. Lee. (2008, March 09). Design For Disaster: The Accordion reCover Shelter, [Online]. Available: http://inhabitat.com/matthew-malone-recovery-shelter/

[7] C. Henry. (2011, September 11). Origami Cave (Emergency Shelter), [Online]. Available: http://www.archdaily.com/166151/origami-cave-emergency-shelter-lava

[8] UNHCR. (2016). How We Shelter, [Online]. Available: www.unhcr.org/how-we-shelter.html

[9] Phiri, (2016, August 17). Dzaleka Refugee Camp Visit [Interview] M. Clark, Interviewer, Malawi.

[10] UNITAR-UNOSAT. (2016, March 07). Kapise Refugee Camp, Mwanza District, Malawi [Online]. Available: http://reliefweb.int/sites/reliefweb.int/files/resources/UNOSAT_A3_Potrait_Kapise_26Feb2016_v2.pdf

[11] R. J. Lang, Origami Design Secrets: Mathematical Methods for an Ancient Art (1). A K Peters Ltd./CRC Press, 2003.

[12] H. Buri and Y. Weinand, "Origami-Folded Plate Structures, Architecture," in Proceedings of the $10^{\text {th }}$ World Conference on Timber Engineering, Miyazaki, Japan, 2008.

[13] C. Vasile and M. Pascu, Practical Guide to Polyethylene. Schrewsbury: RAPRA Technology Ltd., 2005, pp. 31-88.

[14] Zitmar News. (2016, February 02). Malawi: 4000 refugees flee ongoing terror in Mozambique, [Online]. Available: http://zitmar.com/malawi-4000-refugees-flee-terror-in-mozambique 